\title{
11 ¿Como visualiza la productividad y la competitividad en el país?
}

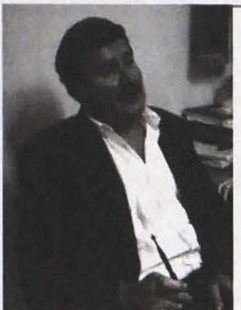

Roberto Rublo, FUNDE
No es una relación mecánica. El que haya más competitividad no quiere decir que haya más productividad, como teóricamente se cree. Lo inverso sí es cierto, a mayor productividad se tiene mayor competitividad, la relación si es directa.

La competitividad hay que buscarla en un sentido amplio. Se puede tener una competitividad estrictamente económica, que se traduce en menores costos y por lo tanto mayores beneficios, pero puede afectar la productividad del suelo, porque ambientalmente se gestiona mal. $\mathrm{O}$ en el área social, creer que es competitivo el tener mano de obra barata, puede afectar la productividad, pues la mano de obra será menos preparada, educada, y con menos acceso a alimentos, por tanto será una población más débil. Hay que tener una visión más amplia de la competitividad que redondee en una productividad más amplia no solo costo- beneficio.

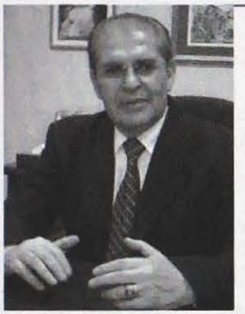

Rafael Rodriguez Loucel, UTEC
La contracción económica "real" se advierte en los siguientes aspectos: En la of erta por un crecimiento promedio del PIB en el período 1996/2004 que ligeramente ha superado el crecimiento poblacional. En ese mismo período y por el lado de la demanda global, por el poco dinamismo y poca diversidad de las exportaciones (con valores anuales significativos), por los reducidos niveles de inversión y finalmente por la prácticamente ausencia de los elementos que hacen que las variables citadas se dinamicen: la productividad y la competitividad; elementos que son consecuencia de la creatividad y de la innovación prácticamente inexistentes y cuya motivación debería surgir principalmente en el empresario.

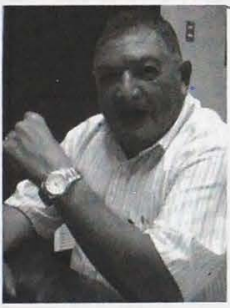

Jorge Barraza Ibarra, UTEC
Se conocen varias concepciones de productividad, comúnmente este término se utiliza para comparar la eficiencia productiva de las empresas, respecto a las cantidades globales de los factores de producción empleados. Pero también hay otros conceptos, tales como el de la productividad multifactorial, la productividad laboral, y también, la productividad marxista derivada del valor trabajo. La concepción común, que parece estar implícita en muchas opiniones en el país, considera que la productividad es el producto físico por trabajador en una empresa o una rama industrial. Aparentemente es útil, pero sin lugar a dudas, es insuficiente, porque ignora el papel que el factor capital y la tecnología utilizada en los procesos de producción, tienen en este aspecto. Los empresarios deben examinar muy cuidadosamente, cuanto les corresponde de responsabilidad en la deficiencia de la productividad de sus empresas. Entonces, la productividad se define como la eficiencia de la producción de un producto, empresa o rama, con respecto a un patrón de producción. Ahora si ésta eficiencia es inferior a la realizada por orros pafses, la competitividad frente al resto del mundo, es definitivamente inferior.

Considerando lo anterior, y volviendo al punto de cómo visualizo la productividad y competitividad en el pais, muy sencilla y francamente, creo que no somos productivos ni comperitivos. 


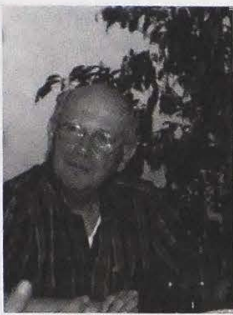

Héctor Dada Hirezi, Diputado CDU
Los datos que se publican al respecto muestran que la productividad media del país ha descendido en los últimos años. Esto nos vuelve comperitivos en sectores de poca complejidad en las acrividades productivas en las que competimos a base de salarios primordialmente. El caso de la intención de traer una empresa electrónica en 1995 , que terminó yendo a Costa Rica, muestra nuestra dificultad en competir en sectores más avanzados y más modernos. Éste problema requiere de un esfuerzo nacional concertado, con la conciencia de que no puede ser enf rentado con programas de corto plazo. Hay que poner sobre la mesa que las obras de infraestructura realizadas sí son un factor favorable a la compecitividad del país, pero con las limitaciones señaladas.

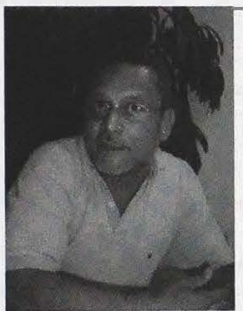

Carios Briones, FLACSO
Son como un buen matrimonio. Definitivamente no puede tenerse una competitividad sostenible en la actual economía mundial globalizada, si no se tienen niveles de productividad crecientes. Siempre habrá alguien que podrá pagar menores salarios. Debe buscarse permanente tener mayores niveles de productividad laboral, para poder ser competitivos, y poder pagar mejores salarios y crear mejores condiciones laborales y de bienestar para la población.

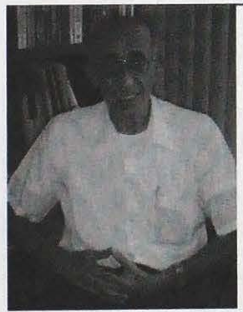

Javier Iblsate, UCA
Daría la impresión que la mayoría de estas preguntas están escogidas para generar respuestas algo tristes. En productividad estamos mal. A este respecto pueden consultarse los últimos capítulos de "La economía Salvadoreña al final del siglo: desafíos para el futuro", Dr. Roberto Rivera Campos. Flacso 2000. E igualmente el último análisis de Fusades 2004, donde se muestra que no levantamos vuelo en el nivel de productividad. Los últimos análisis 2003 de Fusades han insistido en el esfuerzo por la "competitividad". El hecho de que a lo largo de la década de los 90 haya crecido año con año nuestro déficit comercial y que el eje de las exportaciones no haya funcionado ya dice algo de nuestro descuido en mejorar la productividad y comperitividad. Todos somos culpables por negligencia. 